\title{
Hf-Based UiO-66 as Adsorptive Compound and Oxidative Catalyst for Denitrogenation Processes
}

\author{
Rui G. Faria (D), Diana Julião $(\mathbb{D}$, Salete S. Balula *(D) and Luís Cunha-Silva *(D) \\ REQUIMTE/LAQV \& Department of Chemistry and Biochemistry, Faculty of Sciences, University of Porto, \\ 4169-007 Porto, Portugal; up201202396@fc.up.pt (R.G.F.); diananetojuliao@hotmail.com (D.J.) \\ * Correspondence: sbalula@fc.up.pt (S.S.B.); 1.cunha.silva@fc.up.pt (L.C.-S.); Tel.: +351-22-040-2576 (L.C.-S.)
}

\section{check for}

updates

Citation: Faria, R.G.; Julião, D.; Balula, S.S.; Cunha-Silva, L. Hf-Based UiO-66 as Adsorptive Compound and Oxidative Catalyst for Denitrogenation Processes. Compounds 2021, 1, 3-14. https:// doi.org/10.3390/compounds1010002

Received: 17 November 2020

Accepted: 8 January 2021

Published: 19 January 2021

Publisher's Note: MDPI stays neutral with regard to jurisdictional claims in published maps and institutional affiliations.

Copyright: (c) 2021 by the authors. Licensee MDPI, Basel, Switzerland. This article is an open access article distributed under the terms and conditions of the Creative Commons Attribution (CC BY) license (https:// creativecommons.org/licenses/by/ $4.0 /)$.

\begin{abstract}
A series of porous metal-organic frameworks (MOFs) of the UiO-66 family, namely UiO$66(\mathrm{Zr}), \mathrm{UiO}-66(\mathrm{Hf})$ and $\mathrm{UiO}-66(\mathrm{Hf})-\mathrm{NH}_{2}$, prepared by solvothermal procedures were characterized, and their catalytic efficiency for oxidative denitrification (ODN) was investigated for the first time. Sustainable denitrogenation systems combining adsorption and oxidative catalytic capacity were designed using a model diesel containing two distinct nitrogen compounds (NCs) in a solvent-free medium and using an environment-friendly oxidant $\left(\mathrm{H}_{2} \mathrm{O}_{2}\right)$. An efficient adsorptive denitrogenation process was only achieved after long reaction times ( $24 \mathrm{~h}$ ): using the Hf-based MOFs, the adsorptive denitrogenation increased from $19 \%$ to $79 \%$ at 5 to $24 \mathrm{~h}$, while the UiO-66(Zr) reached $76 \%$ after $24 \mathrm{~h}$, although the absence of adsorption capacity after $5 \mathrm{~h}$. UiO-66(Hf) and UiO-66(Hf)- $\mathrm{NH}_{2}$ also revealed superior oxidative catalytic denitrogenation than $\mathrm{UiO}-66(\mathrm{Zr})$, attaining $97 \%$ of efficiency instead of $80 \%$. ODN processes demonstrated to be more effective than the adsorptive denitrogenation, mainly during the first hours of the process. In addition, the metal center in the MOF structure had a larger influence than the presence of the amine-functional groups. Hf-based compounds revealed higher denitrogenation efficiency than the $\mathrm{UiO}-66(\mathrm{Zr})$ for a shorter reaction time $(5 \mathrm{~h})$.
\end{abstract}

Keywords: porous metal-organic frameworks; UiO-66; adsorption; catalytic oxidative denitrogenation; solvent-free; diesel

\section{Introduction}

The complex composition of crude oil containing aromatics with sulfur, nitrogen and/or oxygen compounds is a challenge when selective cleaning treatment procedures need to be applied [1]. A well-known example is the disabling behavior presented by the nitrogen compounds (NCs), which compete with sulfur species during the catalytic desulfurization treatment [2]. NCs are also associated with drastic effects on the environment through the increase of nitrous oxide, a greenhouse gas that contributes to acid rain and smog, which affect metropolitan and remote regions [3]. NCs in crude oil are present in two forms: as heterocyclic aromatic compounds and, in smaller amounts, as non-heterocyclic or aliphatic NCs [4]. The lack of environmental fuel regulations suggests that NCs are tolerated in refined products; however, their toxicity turns their removal crucial to obtain sustainable fossil fuels. Several methods based on extraction, oxidation and adsorption have been investigated to remove NCs from fuels [4]. Oxidation, in particular, is an interesting choice since it can be used in combination with either adsorption or extraction, resulting in an efficient denitrogenation route. The oxidative process, also known as oxidative denitrogenation (ODN), allows the oxidation of the NCs under mild conditions, such as temperatures below $80{ }^{\circ} \mathrm{C}$ and atmospheric pressure [4,5]. Hydrogen peroxide is commonly used as an oxidant due to its innocuous properties (water is the only by-product), availability and high active oxygen content (47\%), only surpassed by molecular oxygen (50\%), which is usually associated with safety concerns [6]. To improve the selectivity of the oxidant for nitrogen atoms, it is important to choose suitable catalysts that offer both good catalytic activity and selectivity and also possess recycling characteristics in order to obtain an efficient and sustainable denitrogenation method. Porous metal-organic frameworks (MOFs) have 
attracted great attention as catalysts in consequence of their well-defined structures, tunable porosity, high surface area and potential post-synthetic modifications [7-9]. In the last years, our research group has been developing sustainable desulfurization processes to treat fuels using MOF-based catalysts [10-16]. In previous reports, the effectiveness of Zr-based UiO-66 (UiO stands for University of Oslo) for the desulfurization of model fuel solutions was demonstrated [11,16,17]. UiO-66(Zr) is composed by self-assembly of 12-connected $\mathrm{Zr}_{6}$ nodes bridged by 1,4-benzene-dicarboxylate (BDC) linkers leading to a tri-dimensional (3D) porous framework of high structural robustness, with the electroneutral formula $\mathrm{Zr}_{6} \mathrm{O}_{4}(\mathrm{OH})_{4}\left(\mathrm{OOC}-\mathrm{C}_{6} \mathrm{H}_{4}-\mathrm{COO}\right)_{6}$ (Figure 1) [18]. In fact, the inorganic block $\mathrm{Zr}_{6}$-octahedra $\left[\mathrm{Zr}_{6} \mathrm{O}_{4}(\mathrm{OH})_{4}\right]$ bounded by twelve organic linkers originates a 3D arrangement of micropores with each octahedral centric cage surrounded by eight corner tetrahedral cages through triangular windows. Typically, the original $\mathrm{UiO}-66(\mathrm{Zr}) \mathrm{MOF}$ reveals a maximum pore diameter of ca. $8.5 \AA$ with an opening window of ca. $6 \AA$, a pore volume of ca. 0.46 and a total of Langmuir of $1187 \mathrm{~m}^{2} \cdot \mathrm{g}^{-1}[18,19]$. The similarity between hafnium(IV) and zirconium(IV) elements results in MOFs with identical structures and the same topology, identical physical properties and stronger bonds with carboxylate groups [20,21]. In addition, the inherent high bond dissociation energy characteristic of both metal bonds ( $\mathrm{Zr}-\mathrm{O}$ and $\mathrm{Hf}-\mathrm{O}$ ) supports their application for Brønsted acid-catalyzed reactions [22,23]. In this context, we expand the application of $\mathrm{UiO}-66(\mathrm{Zr})$ and its parent-framework $\mathrm{UiO}-66(\mathrm{Hf})$ for the oxidative denitrogenation (ODN) of a model diesel using a solvent-free system and $\mathrm{H}_{2} \mathrm{O}_{2}$ as an environmentally friendly oxidant. This structure, when functionalized with amino groups, $\mathrm{UiO}-66(\mathrm{Hf})-\mathrm{NH}_{2}$, can present unique characteristics, from which stands out the increase of potentially unsaturated metal Hf sites, that can have a boosted effect for oxidation and adsorption of NCs during the denitrogenation reactions [24]. Therefore, this amine-functionalized MOF was also applied and compared with its homologs. The most efficient MOF was recycled for five consecutive cycles without loss of activity.
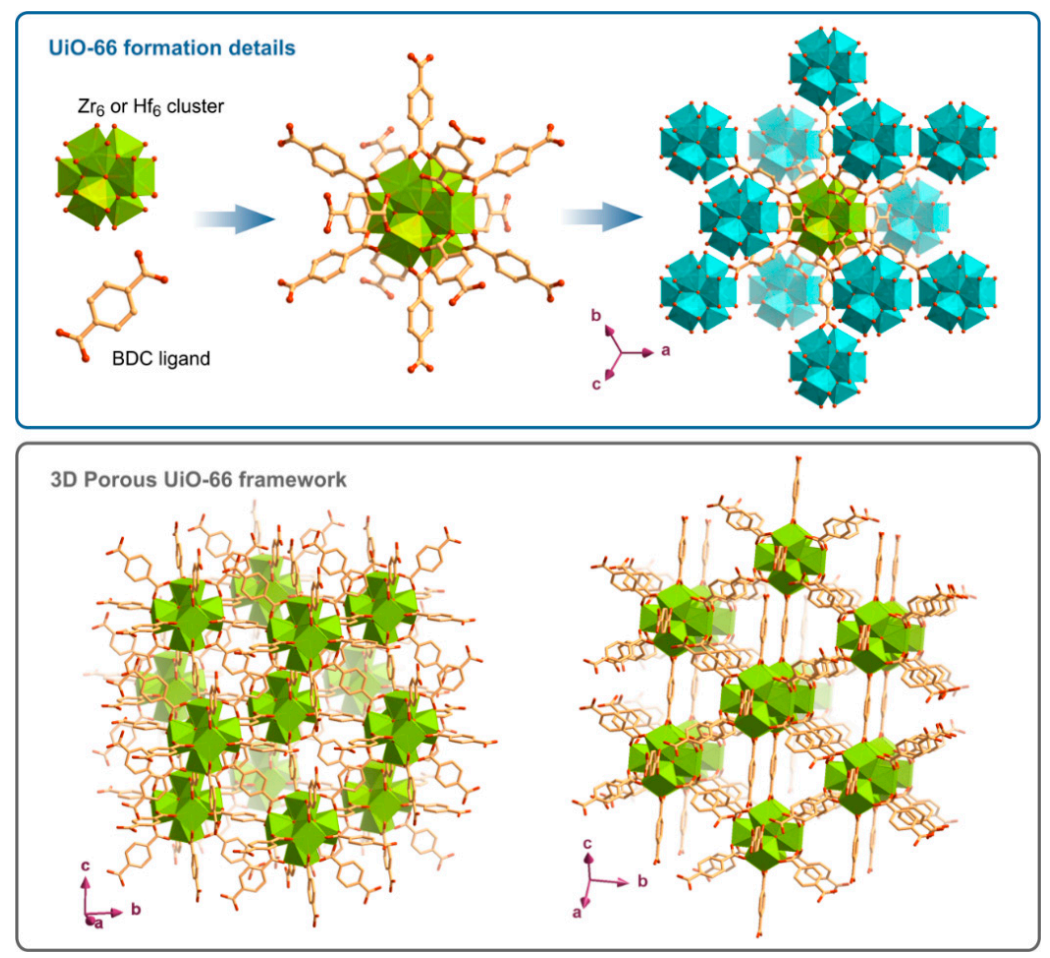

Figure 1. Structural details of the UiO-66-type metal-organic frameworks (MOF) compounds: (top) formation of the MOF from the self-assembly of metal clusters and BCD ligands, showing that each metal cluster (light green) coordinates to 12 others clusters (light blue) leading to an exceptionally robust framework; (bottom) crystal packing arrangement viewed in two distinct directions, revealing the porous features of this family of MOFs. Images prepared from the Crystallographic Information file (CIF) obtained from the Cambridge Structural Database (CSD) with code RUBTAK04. 


\section{Experimental Section}

\subsection{Materials and Methods}

The following chemicals and reagents were purchased from Sigma-Aldrich unless otherwise indicated, and used as received: zirconium(IV) chloride ( $\mathrm{ZrCl}_{4}, \geq 99.5 \%$ ), hafnium(IV) chloride ( $\mathrm{HfCl}_{4}, \geq 99.9 \%$, Alfa Aesar, Kandel, Germany), benzene-1,4-dicarboxylic acid $\left(\mathrm{H}_{2} \mathrm{BDC}, 98 \%\right)$, 2-aminobenzene-1,4-dicarboxylic acid $\left(\mathrm{NH}_{2}-\mathrm{H}_{2} \mathrm{BDC} \mathrm{BDC}, 99 \%\right), \mathrm{N}, \mathrm{N}$ dimethylformamide (DMF, $\geq 99.5 \%$ ), methanol $(\mathrm{MeOH}, \geq 99.9 \%$, Fisher, Loughborough, $\mathrm{UK}$ ), dichloromethane (DCM, $\geq 99.8 \%$, Fisher), ethanol (EtOH, $\geq 99.8 \%$, Fisher) quinoline (QUI, 98\%), indole (IND, $\geq 99 \%$ ), $n$-octane $(98 \%) 30 \mathrm{wt} \%$ hydrogen peroxide $\left(\mathrm{H}_{2} \mathrm{O}_{2}\right)$ and acetonitrile (MeCN, Fisher).

Fourier-transform infrared (FTIR) spectra were acquired on the attenuated total reflectance (ATR) operation mode of a PerkinElmer FTIR system spectrum BX spectrometer, and the spectra representations are shown in arbitrary units of transmittance.

Powder X-ray diffraction (XRD) patterns were obtained at room temperature on a Rigaku SmartLab diffractometer (Faculty of Sciences of University of Porto, Porto, Portugal) operating with a $\mathrm{Cu}$ radiation source $(\lambda=1.540593 \AA)$ and using a Bragg-Brentano $\theta / 2 \theta$ configuration $(45 \mathrm{kV}, 200 \mathrm{~mA})$. The intensity data were collected by a step-counting method (step $0.01^{\circ}$ ), in continuous mode, in the $3 \leq 2 \theta \leq 60^{\circ}$ range, and all representations are shown in arbitrary unities of intensity.

Scanning electron microscopy (SEM) analyses were performed in an FEI Quanta 400 FEG ESEM high-resolution scanning electron microscope (Center of Materials of University of Porto, Porto, Portugal). Energy-dispersive X-ray spectroscopy (EDX) studies were carried out in the same microscope working at $10 \mathrm{keV}$ and using an EDAX Genesis $\mathrm{X} 4 \mathrm{M}$ microanalysis system. Samples were coated with an $\mathrm{Au} / \mathrm{Pd}$ thin film by sputtering using SPI module sputter coater equipment (Center of Materials of University of Porto, Porto, Portugal).

Catalytic reactions were periodically monitored by GC-FID analysis carried out in a Bruker 430-GC-FID chromatograph (Faculty of Sciences of University of Porto, Porto, Porto, Portugal). Hydrogen was used as carrier gas $\left(55 \mathrm{~cm} \cdot \mathrm{s}^{-1}\right)$, and fused silica Supelco capillary columns SPB-5 ( $30 \mathrm{~m} \times 0.25 \mathrm{~mm}$ i. d.; $25 \mu \mathrm{m}$ film thickness) were used.

\subsection{Synthesis of MOFs}

\subsection{1. $\mathrm{UiO}-66(\mathrm{Zr})$}

UiO-66(Zr) was prepared by a procedure based on previously published reports by our research group $[11,16,17]$. Briefly, a solution of $\mathrm{ZrCl}_{4}(0.53 \mathrm{mmol})$ and $\mathrm{BDC}(0.53 \mathrm{mmol})$ in DMF $(15 \mathrm{~mL})$ was prepared at room temperature. After $15 \mathrm{~min}$ under stirring, the solution was placed in a Teflon-lined autoclave and heated in an oven at $120^{\circ} \mathrm{C}$ for $24 \mathrm{~h}$. After this reaction period, it was left cooling to room temperature, and the white solid obtained was filtered, washed three times with DMF and $\mathrm{MeOH}$ each, and dried at $60{ }^{\circ} \mathrm{C}$ under vacuum overnight. Selected FTIR peaks $\left(\mathrm{cm}^{-1}\right): v=1658(\mathrm{~s}), 1582(\mathrm{~s}), 1504(\mathrm{w})$, 1390 (vs), 748 (vs), 664 (s), 555 (m), 548 (m), 475 (s).

\subsection{2. $\mathrm{UiO}-66(\mathrm{Hf})$}

UiO-66(Hf) was prepared using a solvothermal approach, as described by Cliffe et al. [25]. Succinctly, $\mathrm{HfCl}_{4}(0.49 \mathrm{mmol})$ and BDC $(0.49 \mathrm{mmol})$ were joined in a Teflon-lined autoclave, followed by a mixture of DMF and formic acid $(18 / 2, v / v)$. The mixture was magnetically stirred at room temperature for $15 \mathrm{~min}$ and placed in an oven at $123^{\circ} \mathrm{C}$ for $40 \mathrm{~h}$. After cooling to room temperature, the white solid was isolated by filtration and purified with $\mathrm{MeOH}$ and with DCM ( 3 days of immersion in each solvent and refreshing the solvent every day), and finally dried and activated at $120^{\circ} \mathrm{C}$ under vacuum for $24 \mathrm{~h}$. Selected FTIR peaks $\left(\mathrm{cm}^{-1}\right): v=1656(\mathrm{w}), 1578(\mathrm{~s}), 1504(\mathrm{w}), 1396$ (vs), 745 (vs), 669 (s), 553 (m), 474 (s). 


\subsubsection{UiO-66(Hf)- $\mathrm{NH}_{2}$}

UiO-66(Hf)- $\mathrm{NH}_{2}$ was synthesized following a previously reported procedure with slight modifications [26]. Briefly, a solution of $\mathrm{HfCl}_{4}(5.2 \mathrm{mmol})$ and $\mathrm{NH}_{2}-\mathrm{BDC}(5.0 \mathrm{mmol})$ in water and acetic acid $(30 / 20, v / v)$ was maintained under reflux and continuous magnetic stirring for $24 \mathrm{~h}$. After the reaction was completed, the solid was filtered and purified, dried and activated as described for the UiO66-(Hf) already described. Selected FTIR peaks $\left(\mathrm{cm}^{-1}\right)$ : v = $1696(\mathrm{w}), 1570(\mathrm{~s}), 1496(\mathrm{w}), 1388(\mathrm{vs}), 1336(\mathrm{vw}), 1257(\mathrm{w}), 763(\mathrm{vs}), 679(\mathrm{~s})$, $572(\mathrm{w}), 474(\mathrm{~s})$.

\subsection{Oxidative Denitrogenation (ODN)}

The ODN experiments were performed using a model diesel composed of $400 \mathrm{ppm}$ of $\mathrm{N}$ from two different NCs, a basic compound with a five-membered pyrrole (IND, $200 \mathrm{ppm}$ of N) and a neutral one with a six-membered pyridine (QUI, $200 \mathrm{ppm}$ ) (Scheme 1), which were dissolved in $n$-octane. Model diesel $(1 \mathrm{~mL})$ and catalyst $(5 \mathrm{mg})$ were added in a 5-mL borosilicate vessel under atmospheric pressure, followed by $\mathrm{H}_{2} \mathrm{O}_{2}(0.11 \mathrm{mmol}$, ratio $\mathrm{H}_{2} \mathrm{O}_{2} / \mathrm{N}=4$ ) at $70{ }^{\circ} \mathrm{C}$. The reactions were magnetically stirred and immersed in a thermostatically controlled liquid paraffin bath. The periodic quantification of nitrogen content was analyzed by GC by injection of aliquots ( $10 \mu \mathrm{L}$ of diesel diluted in tetradecane) extracted during the ODN reactions. The reusability tests were performed by the removal of the solid catalyst by centrifugation at the end of each cycle and posterior reuse of this solid after a cleaning process involving $\mathrm{MeCN}$ and $\mathrm{EtOH}$. The recycling cycles were performed under the same initial conditions, i.e., the addition of fresh portions of model diesel and $\mathrm{H}_{2} \mathrm{O}_{2}$. In the case of adsorption experiments, a similar procedure was applied, i.e., using 1-mL model diesel and $5 \mathrm{mg}$ of catalyst in the absence of oxidant and under room temperature $\left(25^{\circ} \mathrm{C}\right)$.
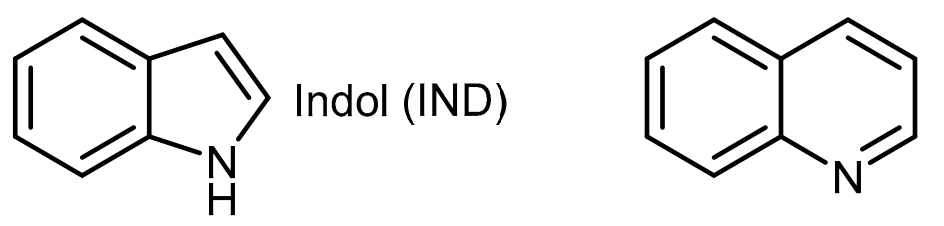

\section{Quinoline (QUI)}

Scheme 1. Chemical structures of the nitrogen compounds (NCs) used: indol (IND) and quinoline (QUI).

\section{Results and Discussion}

\subsection{MOF Characterization}

The parent MOF compounds $\mathrm{UiO}-66(\mathrm{Zr}), \mathrm{UiO}-66(\mathrm{Hf})$ and $\mathrm{UiO}-66(\mathrm{Hf})-\mathrm{NH}_{2}$ were synthesized by solvothermal strategy and rigorously characterized and analyzed by a complementary set of structural methods, such as FTIR spectroscopy, powder X-ray diffraction (XRD), scanning electron microscopy (SEM) and energy-dispersive X-ray (EDX) spectroscopy. As shown in Figure 2a, the FTIR spectra of the UiO-66-type compounds reveal a similar profile, with the main infrared bands matching previous reports. The absorption bands at $1580 \mathrm{~cm}^{-1}$ and $1400 \mathrm{~cm}^{-1}$ are attributed to the stretching vibration of the coordinated $\mathrm{C}-\mathrm{O}$ group, while at $1500 \mathrm{~cm}^{-1}$ and $763 \mathrm{~cm}^{-1}$, the stretching vibration of $\mathrm{C}=\mathrm{C}$ from the benzene ring is clearly observed, both characteristic of the BDC ligands $[23,27]$. The band corresponding to metal ( $\mathrm{Hf}$ or $\mathrm{Zr}$ )-oxygen stretching is present in the $580-550 \mathrm{~cm}^{-1}$ region. The incorporation of amine groups in $\mathrm{UiO}-66(\mathrm{Hf})-\mathrm{NH}_{2}$ was also examined and confirmed by $\mathrm{C}-\mathrm{N}$ stretching absorptions at 1336 and $1254 \mathrm{~cm}^{-1}$, indicative of aromatic amines $[28,29]$. In the FTIR spectra of MOFs prepared with DMF (UiO-66(Zr) and UiO$66(\mathrm{Hf})$ ) and acetic acid (UiO-66(Hf)- $\left.\mathrm{NH}_{2}\right)$, an absorption band was observed at $1656 \mathrm{~cm}^{-1}$ related to the $\mathrm{C}=\mathrm{O}$ bond. This can be related to a small amount of zirconium or hafnium solvent adduct formed during the synthesis of MOFs that due to unexchanged BDC ligands, kept coordinated to the metal at the end of the purification and activation processes [30,31]. This phenomenon can also be corroborated by the powder XRD (Figure 2b) patterns of the various UiO-66 samples prepared with DMF, in which it is possible to observe a very 
small broad peak at $2 \theta=10^{\circ}-12^{\circ}$ [32,33]. In general, the MOFs showed similar powder diffraction patterns, exhibiting the typical diffraction peaks of UiO-66 in terms of position and relative intensities. Both FTIR spectra and powder XRD confirm the preparation of the desired compounds.

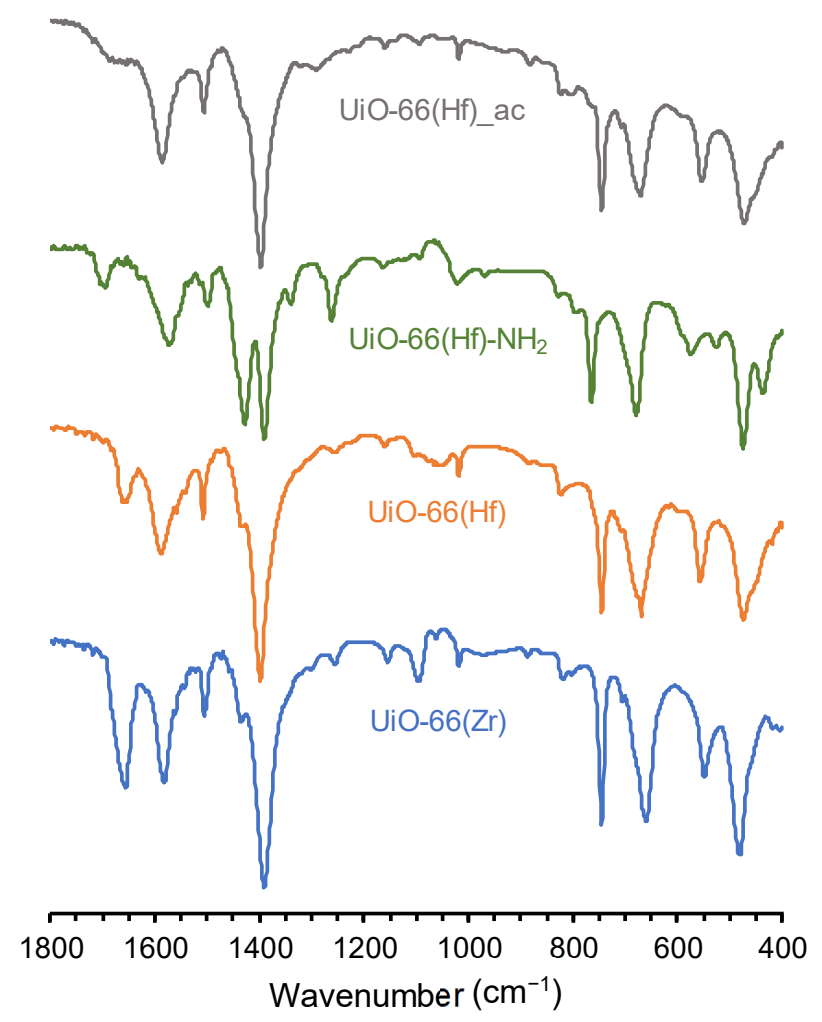

(a)

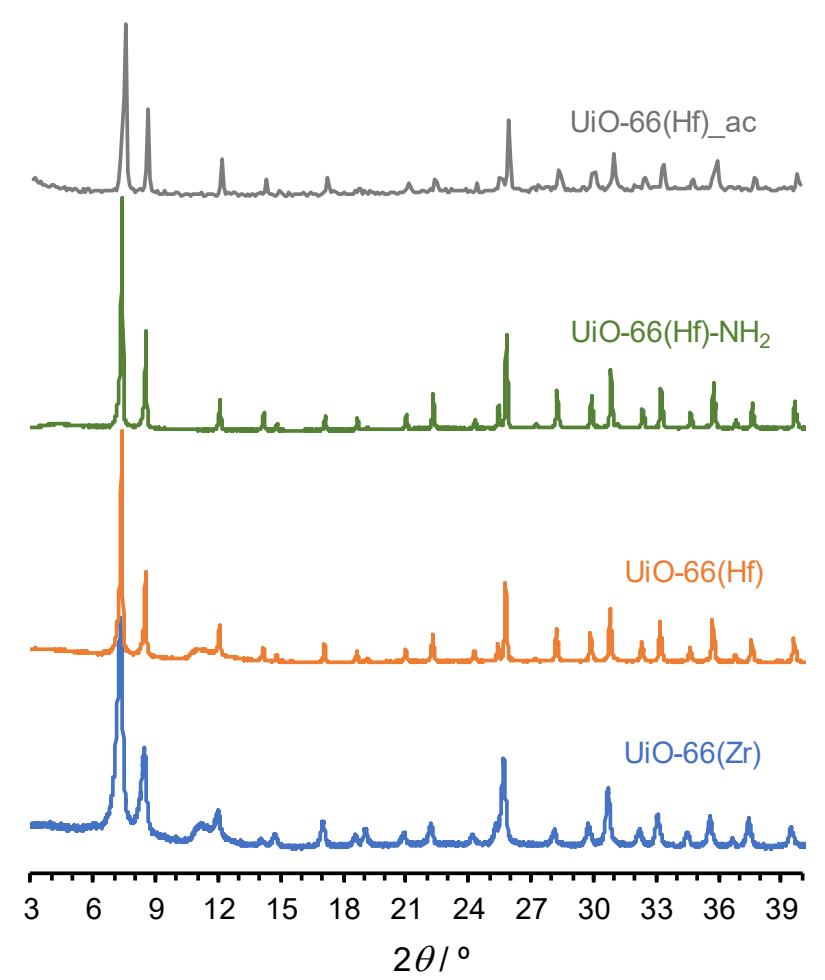

(b)

Figure 2. (a) FTIR spectra and (b) powder XRD patterns of the UiO-66 compounds: UiO-66(Zr), UiO-66(Hf), UiO-66(Hf)$\mathrm{NH}_{2}$ and UiO-66(Hf)_ac (ac stands for after catalysis).

The SEM images of all UiO-66-type compounds reveal the presence of highly agglomerated nanoparticles (Figure 3). However, the small differences in terms of the edges of the nanoparticles could be related to different solvents used during each compound preparation. Additionally, the EDX analysis of each compound revealed the presence of the metal nodes characteristic of each UiO-66, i.e., zirconium or hafnium, while the characterization of the UiO-66(Hf)- $\mathrm{NH}_{2}$ also showed the presence of nitrogen arising from $-\mathrm{NH}_{2}$ group. 


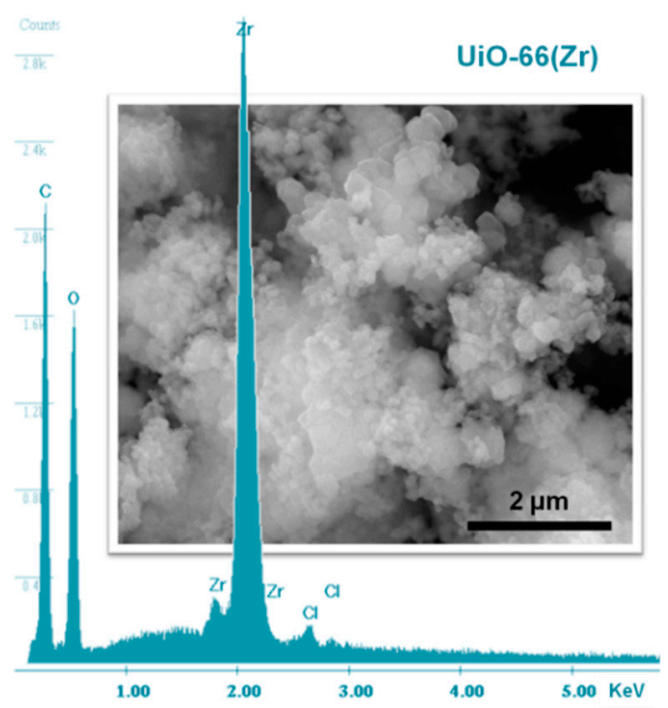

(a)

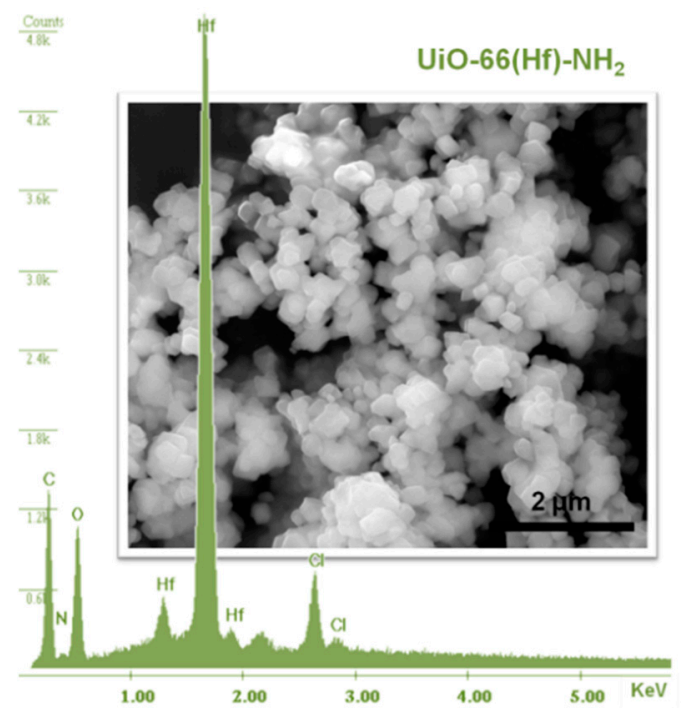

(c)

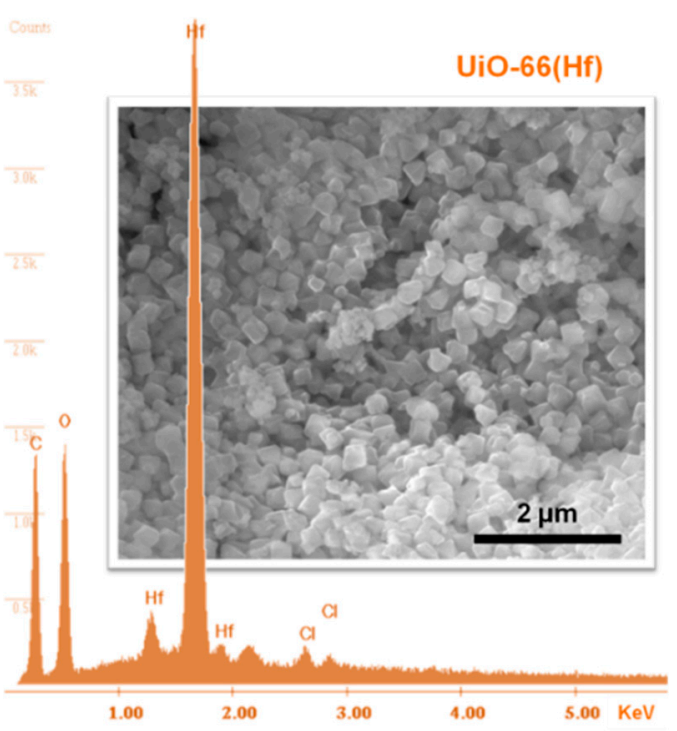

(b)

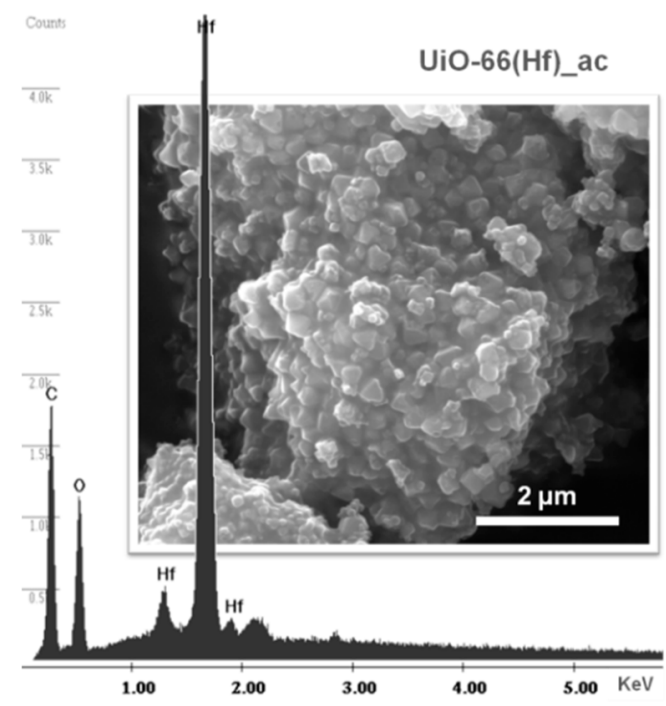

(d)

Figure 3. SEM images and respective EDX spectra of the various UiO-66: (a) UiO-66( $\mathrm{Zr}),(\mathbf{b}) \mathrm{UiO}-66(\mathrm{Hf}),(\mathbf{c}) \mathrm{UiO}-66(\mathrm{Hf})-\mathrm{NH}{ }_{2}$ and (d) UiO-66(Hf)_ac (ac stands for after catalysis).

\subsection{Denitrogenation Studies}

\subsubsection{Adsorptive Denitrogenation}

The first step of the denitrogenation studies was the evaluation of the adsorption capacity of each UiO-66-based compound. Figure 4a displays the adsorptive denitrogenation of the model diesel in the presence of the various MOFs for $24 \mathrm{~h}$. Some differences in adsorption capacity are observed during the first $5 \mathrm{~h}$, with the two Hf-based MOFs revealing a slightly higher adsorptive ability (19\% of nitrogen removal) than the UiO-66(Zr). In fact, this compound showed an absence of adsorption capacity at this period of time. However, the adsorptive capacity of this family of porous MOFs increased significantly after the first hours, and after $24 \mathrm{~h}$, similar adsorptive denitrogenation results were obtained for all the UiO-66 compounds investigated, with results from $76 \%$ to $79 \%$. Although a similar global efficiency has been found, there are considerable differences in adsorption capacity achieved for each NC (Figure $4 \mathrm{~b}$ ). In fact, the removal of QUI from model diesel followed the order: $\mathrm{UiO}-66(\mathrm{Hf})(80.6 \%)>\mathrm{UiO}-66(\mathrm{Zr})(76.6 \%)>\mathrm{UiO}-66(\mathrm{Hf})-\mathrm{NH}_{2}(68.6 \%)$. Interestingly, in the case of IND, a reverse behavior was observed, and a near-complete 
removal $(98.0 \%)$ was attained in the presence of the amine-functionalized MOF, while in the presence of the other two compounds, the adsorption values were very similar $(\cong 74.0 \%)$. The removal of NCs by MOFs have been explained based on $\mathrm{H}$-bonding, which are known to be improved in the presence of functional groups, such as $-\mathrm{NH}_{2},-\mathrm{OH},-\mathrm{COOH}, \mathrm{SO}_{3} \mathrm{H}$, among others [34]. In this case, the superior adsorption capacity obtained for IND with amine-functionalized MOF most probably resulted from the formation of a hydrogen bond between the $\mathrm{N}$-atom of $\mathrm{UiO}-66(\mathrm{Hf})-\mathrm{NH}_{2}$ with the $\mathrm{H}$ atom from the $\mathrm{N}$ group from IND (Figure 5) [29,34]. The same behavior was not observed for QUI due to possible base-base repulsion between the basic NC and the basic amino group of the MOF [29].

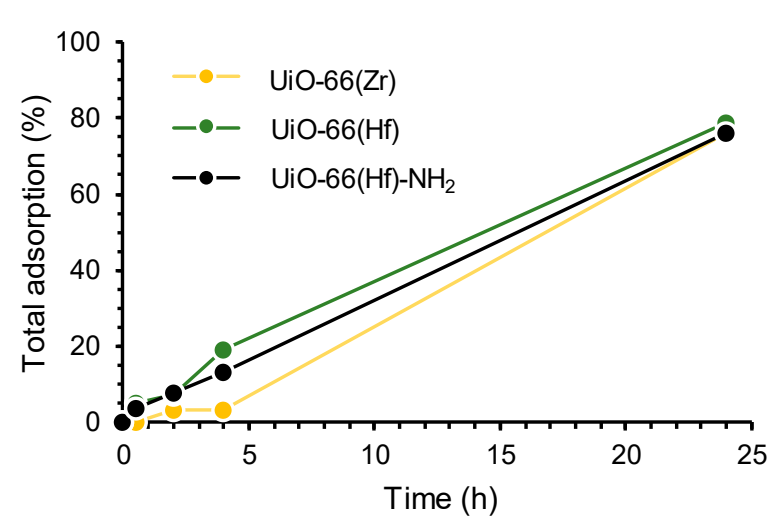

(a)

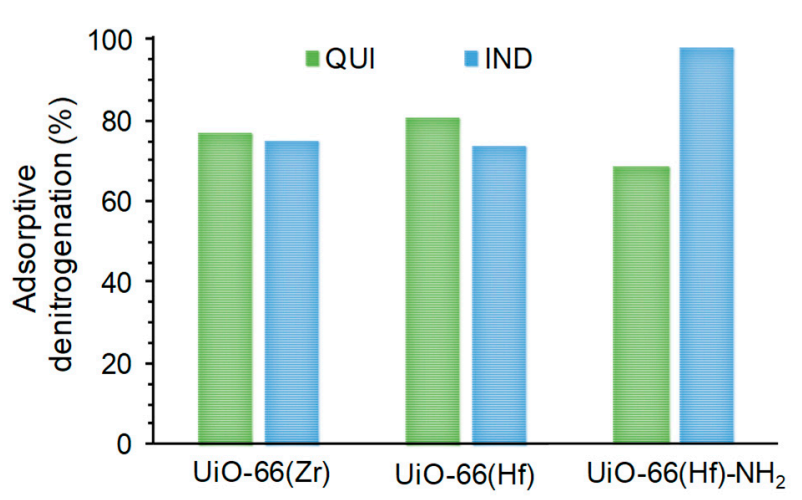

(b)

Figure 4. (a) Adsorptive denitrogenation profile of a model diesel containing 200 ppm of N from IND and 200 ppm of N from QUI, using different UiO-66 compounds as adsorbents under $25^{\circ} \mathrm{C} ;(\mathbf{b})$ adsorptive capacity of MOFs for each NC at $24 \mathrm{~h}$.

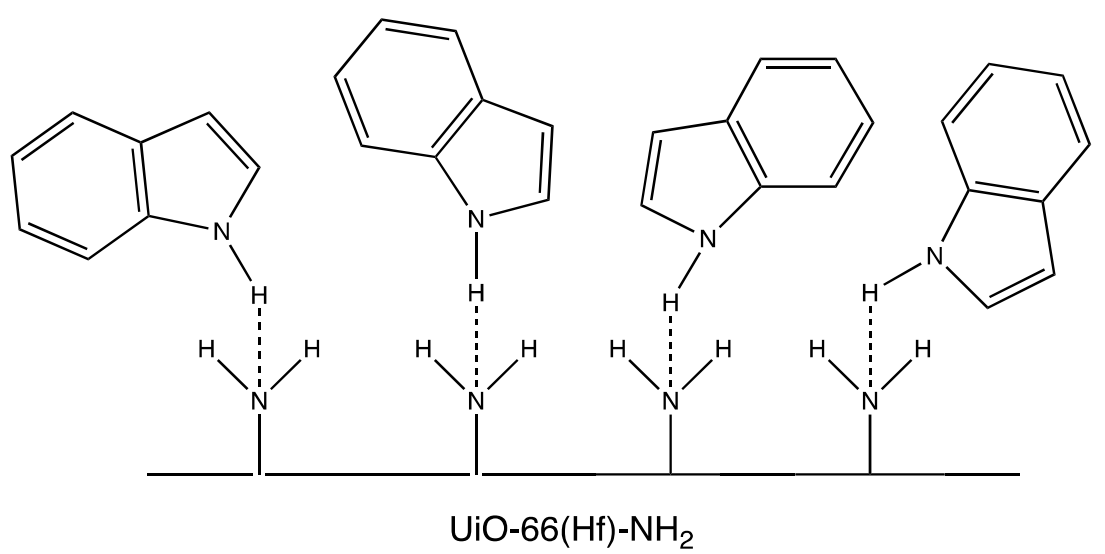

Figure 5. Schematic explanation of the H-bond interaction between the IND and amino groups of UiO-66(Hf)- $\mathrm{NH}_{2}$ (based on reference number [34]).

\subsubsection{Oxidative Denitrogenation}

Although a high adsorptive denitrogenation efficiency of the UiO-66 family of MOFs has been achieved after $24 \mathrm{~h}$, at industrial point of view it is disadvantageous, since long reaction time means low cost-efficiency and low viability. Continuing the search for alternative efficient processes which is the main target of the present work, the prepared MOFs were applied as catalysts for oxidative catalytic process (known for improving efficiency under short reaction times). Recently, we demonstrated that UiO-66(Zr) MOF is an active heterogeneous catalyst for oxidative desulfurization, achieving high sulfur removals using $\mathrm{H}_{2} \mathrm{O}_{2}$ as oxidant $[11,16,17]$. Following an identical study line and concerning the importance of optimization studies for denitrogenation efficiency, in this work, we used the same compound $\mathrm{UiO}-66(\mathrm{Zr})$ as a heterogeneous catalyst for the initial oxidation of NCs 
approach. To the petroleum refining industry, the control of some parameters is important in order to reduce possible costs and environmental problems. A good example is a temperature, which should be maintained below $80^{\circ} \mathrm{C}$ to avoid the degradation of some fuel constituents responsible for quality properties. Using the multicomponent model diesel (400 ppm N), the UiO-66( $\mathrm{Zr}$ ) was tested as a catalyst at different reaction temperatures, using $\mathrm{H}_{2} \mathrm{O}_{2}(0.11 \mathrm{mmol})$ as oxidant (Figure 6). The solvent-free system using UiO-66( $\mathrm{Zr}$ ) catalyst was promoted by the increase of temperature from $50{ }^{\circ} \mathrm{C}$ to $70{ }^{\circ} \mathrm{C}$, which resulted in a nitrogen oxidation rate of $80.1 \%$ after $5 \mathrm{~h}$ of reaction (only $92 \mathrm{ppm}$ of $\mathrm{N}$ remained in the model diesel after $2 \mathrm{~h}$ ). On the other hand, between $25^{\circ} \mathrm{C}$ to $50^{\circ} \mathrm{C}$, the conversion was practically maintained. The increase of temperature from $50^{\circ} \mathrm{C}$ to $70^{\circ} \mathrm{C}$ has a direct effect on kinetic rate constant, benefiting the formation of peroxide metal complexes and consequently enhancing the NCs oxidation [27].

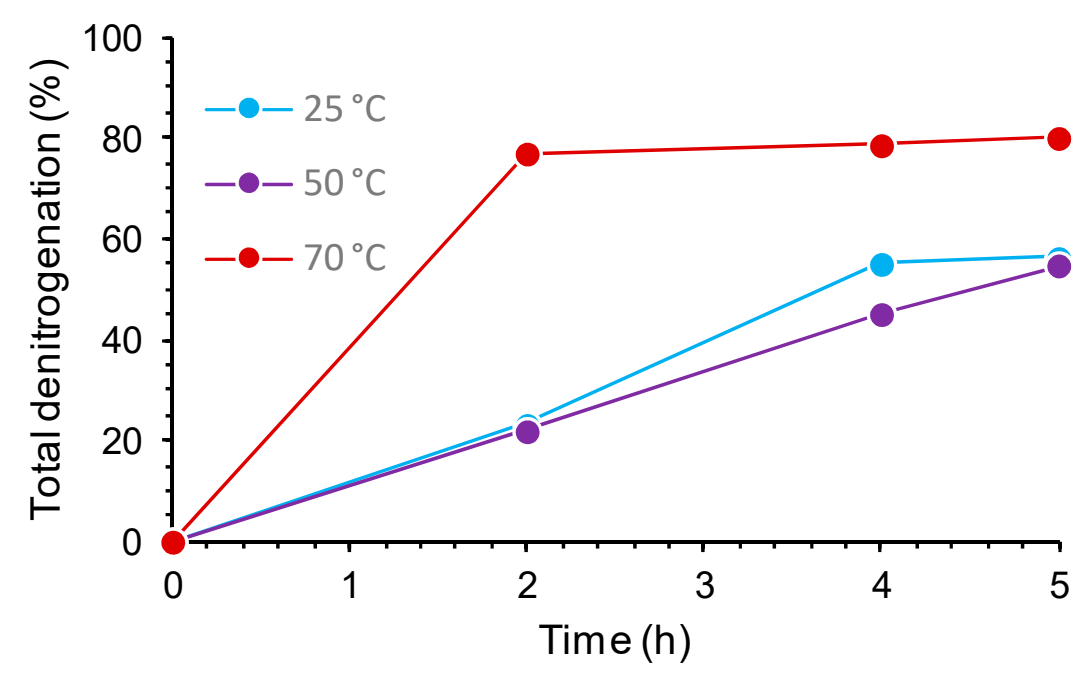

Figure 6. Total denitrogenation (ODN) of a model diesel with $200 \mathrm{ppm}$ of $\mathrm{N}$ from IND and $200 \mathrm{ppm}$ of $\mathrm{N}$ from QUI, using $\mathrm{UiO}-66(\mathrm{Zr})(5 \mathrm{mg})$ as catalyst, $\mathrm{H}_{2} \mathrm{O}_{2}(0.11 \mathrm{mmol})$ as oxidant, under different reaction temperatures $\left(25,50\right.$ and $\left.70^{\circ} \mathrm{C}\right)$.

The denitrogenation performances of all UiO-66 frameworks, UiO-66(Zr), UiO-66(Hf) and $\mathrm{UiO}-66(\mathrm{Hf})-\mathrm{NH}_{2}$, were analyzed using the optimized temperature $\left(70{ }^{\circ} \mathrm{C}\right)$ and maintaining the remaining experimental conditions (model diesel $=1 \mathrm{~mL}$, catalyst $=5 \mathrm{mg}$, $0.11 \mathrm{mmol}$ of $\mathrm{H}_{2} \mathrm{O}_{2}$ and reaction time of $5 \mathrm{~h}$ ), Figure $7 \mathrm{a}$. Both the hafnium-based catalysts revealed a high and similar catalytic performance for NCs oxidation, allowing the oxidative conversion of more than $94.6 \%$ of the initial $400 \mathrm{ppm}$ nitrogen content. Brønsted acidity is known to have a fundamental role in acid-catalyzed reactions. Thus, the different catalytic behavior observed between hafnium and zirconium MOFs is probably a result of different Brønsted acidities, which is higher in Hf-clusters due to a higher oxophilicity of Hf(IV) [35]. This higher oxophilicity of Hf(IV) is probably generated by its higher structural defect points that create linker vacancies, which are compensated with hydroxide or water ligands( $\mathrm{Hf}-\mathrm{OH}$ and $\left.\mathrm{Hf}-\mathrm{OH}_{2}\right)$. These last promote an easier interaction with the $\mathrm{H}_{2} \mathrm{O}_{2}$ oxidant and NCs, increasing catalyst efficiency. 


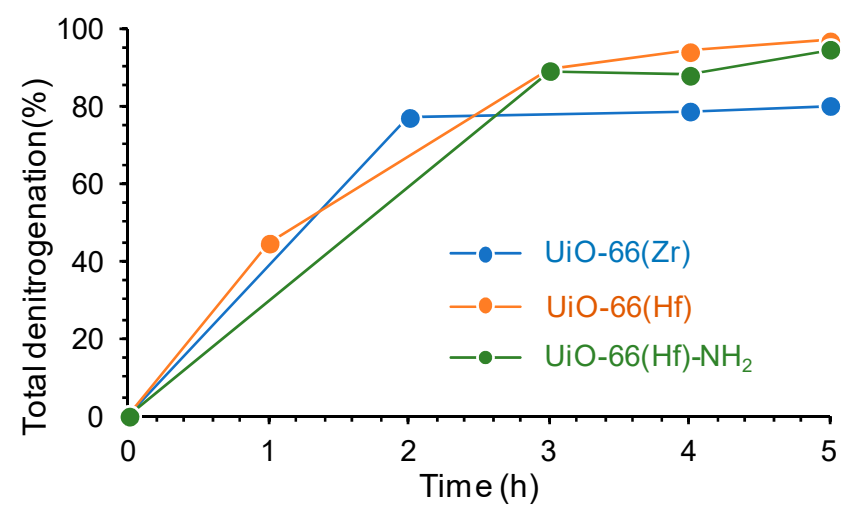

(a)

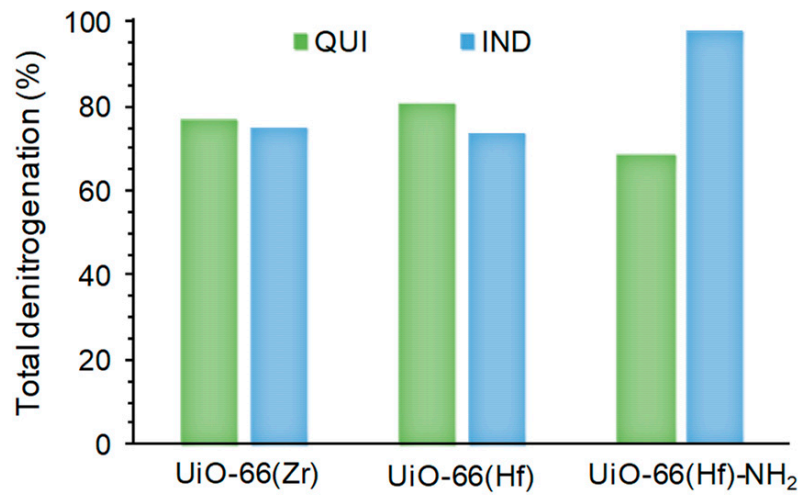

(b)

Figure 7. (a) Total denitrogenation (ODN) profile of a model diesel with $200 \mathrm{ppm}$ of $\mathrm{N}$ from IND and $200 \mathrm{ppm}$ of $\mathrm{N}$ from QUI, using various UiO-66 frameworks as catalysts $(5 \mathrm{mg}), \mathrm{H}_{2} \mathrm{O}_{2}(0.11 \mathrm{mmol})$ as oxidant, at $70{ }^{\circ} \mathrm{C}$; (b) oxidative denitrogenation results obtained for each NC after $5 \mathrm{~h}$ of reaction.

The reaction performed in the absence of catalyst resulted in a total nitrogen conversion of ca $70 \%$. This value could reflect an easy oxidative procedure for both NCs. However, under the blank conditions (absence of catalyst), only $27 \%$ of the QUI was oxidized after $5 \mathrm{~h}$ of reaction, and this result is not increased largely after this reaction time, indicating that $\mathrm{UiO}-66$ have a perennial effect as oxidative catalysts.

Using real diesel samples, the presence of catalysts is crucial to guarantee high denitrogenation performance but also to prevent non-selective oxidative reactions resulting by $\mathrm{H}_{2} \mathrm{O}_{2}$ instability that easily causes possible side reactions. The oxidative denitrogenation efficiency for each NC is shown in Figure $7 \mathrm{~b}$. The conversion of IND is slightly higher than the QUI in the presence of all the UiO-66 catalysts. This is even more noticiable in the presence of the $\mathrm{UiO}-66(\mathrm{Zr})$ catalyst.

Correlating the adsorptive denitrogenation performance of these UiO-66 compounds (Figure 4a) with their oxidative catalytic efficiency (Figure 7a), it is possible to verify that after $5 \mathrm{~h}$, the UiO-66( $\mathrm{Zr})$ is the less efficient in both processes. In fact, this last MOF in a short process time as $5 \mathrm{~h}$ only presents oxidative denitrogenation effect. The aminefunctionalized $\mathrm{UiO}-66(\mathrm{Hf})-\mathrm{NH}_{2}$ reveals a slightly superior adsorptive denitrogenation than the non-functionalized $\mathrm{UiO}-66(\mathrm{Hf})$, but in the oxidative catalytic process, its superior adsorptive capacity is negligible, and a similar denitrogenation performance to the UiO66(Hf) was achieved.

In view of the excellent catalytic performance obtained for hafnium-based UiO-66 compounds, the recycling capacity was evaluated for five consecutive cycles, selecting the non-functionalized UiO-66(Hf) for this study. At the end of each cycle, the catalyst was recovered from the reaction medium by centrifugation and washed several times with $\mathrm{MeCN}$ and $\mathrm{EtOH}$, dried and reused in a new catalytic cycle under the same experimental conditions with fresh portions of model diesel $(1 \mathrm{~mL})$ and $\mathrm{H}_{2} \mathrm{O}_{2}(0.11 \mathrm{mmol})$. The results of the recycling study revealed that the $\mathrm{UiO}-66(\mathrm{Hf})$ is recyclable, maintaining practically constant activity over the five cycles, i.e., $96.7 \%, 93.6 \%, 89.0 \%, 89.6 \%$ and $99.3 \%$ after $5 \mathrm{~h}$ of reaction (Figure 8). The last cycle resulted in a model diesel with only 3 ppm of NCs. 


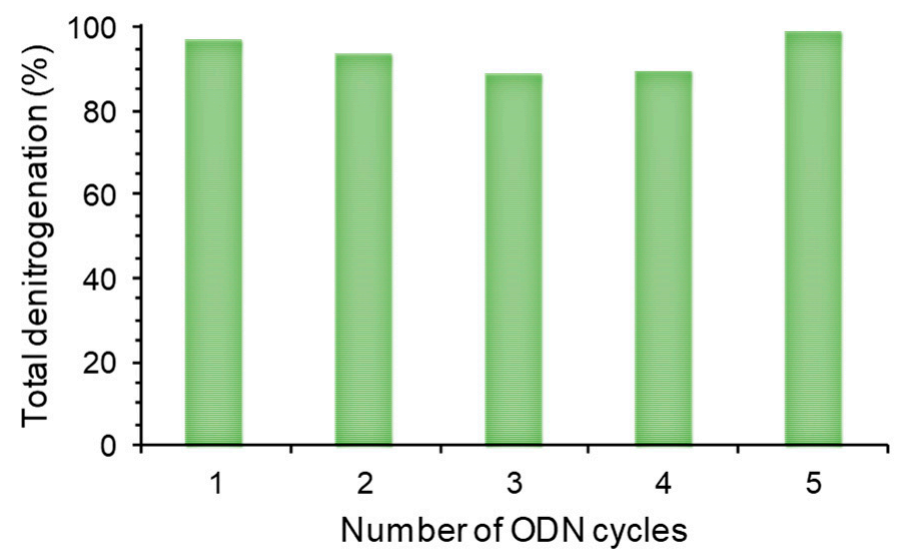

Figure 8. Total denitrogenation data for five consecutive recycled cycles, using a model diesel with 200 ppm of $\mathrm{N}$ from IND and 200 ppm of $\mathrm{N}$ from QUI, catalyzed by UiO-66(Hf) (5 mg) with $\mathrm{H}_{2} \mathrm{O}_{2}$ as oxidant $(0.11 \mathrm{mmol})$, at $70^{\circ} \mathrm{C}$.

The characterization of the compound recovered after the five recycling cycles, $\mathrm{UiO}-$ 66(Hf)_ac, confirmed the structural stability of the compound after the ODN experiment (Figures 2 and 3). The FTIR spectrum of UiO-66(Hf)_ac did not reveal significant differences from the compound before catalysis application, with the exception of the absorption band assigned to $\mathrm{C}=\mathrm{O}$ from $\mathrm{DMF}$ solvent that decreased substantially. This can be related to solvent exchange, as a result of the application on the catalytic reaction medium, and posterior washing procedures between cycles. The powder XRD pattern of the compound after catalysis showed a similar profile, with the retention of the main diffraction peaks and intensity. The morphology and chemical composition of UiO-66(Hf)_ac was also verified by SEM/EDX, which indicated no evidence of degradation and identical elemental composition to that observed for UiO-66(Hf) before catalytic use. Therefore, the hafniumbased UiO-66 showed to be a structural stable heterogeneous catalyst and resistant to oxidative denitrogenation under the applied conditions.

\section{Concluding Remarks}

A family of UiO-66 MOFs compounds incorporating zirconium and hafnium metal centers was prepared and used as adsorptive and oxidative catalytic compounds to remove nitrogen compounds (NCs) from a model diesel containing the most representative nitrogen compounds in real fuels, i.e., indole and quinoline ( $400 \mathrm{ppm}$ of $\mathrm{N})$. Effective adsorptive denitrogenation was only found after several hours, increasing from $19 \%$ at $5 \mathrm{~h}$ to $79 \%$ after $24 \mathrm{~h}$, using UiO-66(Hf). Similar adsorptive denitrogenation results were found for both NCs, with the exception for the amine-functionalized UiO-66(Hf), which revealed a high adsorption capability for IND, probably due to a hydrogen bond interaction. To turn the denitrogenation process industrially more viable and more cost-effective, the time of the process was decreased to $5 \mathrm{~h}$, and the UiO-66 family was effectively applied as oxidative catalysts in the presence of a sustainable oxidant $\left(\mathrm{H}_{2} \mathrm{O}_{2}\right)$, resulting in an increased efficiency. Under these conditions, the NCs were removed from the model diesel with $97 \%$ efficiency. Highest oxidative denitrogenation performances were attained for UiO-66(Hf) compounds, while the zirconium-based UiO-66 revealed a poor behavior. The Hf-based MOF revealed to be stable and capable to be recycled for five consecutives cycles without loss of activity. Although the UiO-66(Hf) compounds have presented high adsorptive and oxidative denitrogenation efficiencies, the MOFs-adsorptive capacity showed to be negligible at short reaction times $(<5 \mathrm{~h})$ prevailing the oxidative catalytic performance. In fact, the UiO-66(Hf) MOF demonstrated high viability for industrial application, forming a denitrogenation system that conciliates high-efficiency, sustainable functionality, recyclability and robustness. Based on the promising results obtained in both 
adsorptive and oxidative denitrogenation studies, further work will be developed using Hf-based UiO-66 compounds functionalized with different functional groups.

Author Contributions: R.G.F. performed most part of the laboratory and instrumental work, specifically the preparation and characterization of several UiO-66( $\mathrm{Zr})$ compounds, as well as the denitrogenation experiments; D.J. was accompanied all laboratory work and prepared the first version of the manuscript; S.S.B. was responsible by the coordination of the oxidative denitrogenation studies and also by the submitted version of the manuscript; L.C.-S. coordinated the synthesis and characterization of the MOF compounds, as well as the preparation of this manuscript. All authors have read and agreed to the published version of the manuscript.

Funding: This work was partly funded within the scope of the strategic project of LAQV-REQUIMTE (UID/QUI/50006/2019) and the R\&D project GlyGold (PTDC/CTM-CTM/31983/2017), financed by national funds through the FCT/MCTES-Portuguese Foundation for Science and Technology and, when appropriate, co-financed by FEDER (Fundo Europeu de Desenvolvimento Regional) under the PT2020 Partnership Agreement.

Conflicts of Interest: The authors declare no conflict of interest.

\section{References}

1. Srivastava, V.C. An evaluation of desulfurization technologies for sulfur removal from liquid fuels. RSC Adv. 2012, 2, 759-783. [CrossRef]

2. Laredo, G.C.; Altamirano, E.; De los Reyes, J.A. Inhibition effects of nitrogen compounds on the hydrodesulfurization of dibenzothiophene: Part 2. Appl. Catal. A Gen. 2003, 243, 207-214. [CrossRef]

3. Vitousek, P.M.; Mooney, H.A.; Lubchenco, J.; Melillo, J.M. Human Domination of Earth's Ecosystems. Science 1997, $277,494-499$. [CrossRef]

4. Prado, G.H.C.; Rao, Y.; de Klerk, A. Nitrogen Removal from Oil: A Review. Energy Fuels 2017, 31, 14-36. [CrossRef]

5. Bertleff, B.; Haider, M.S.; Claußnitzer, J.; Korth, W.; Wasserscheid, P.; Jess, A.; Albert, J. Extractive Catalytic Oxidative Denitrogenation of Fuels and Their Promoting Effect for Desulfurization Catalyzed by Vanadium Substituted Heteropolyacids and Molecular Oxygen. Energy Fuels 2020, 34, 8099-8109. [CrossRef]

6. Sheldon, R.A. Homogeneous and heterogeneous catalytic oxidations with peroxide reagents. In Organic Peroxygen Chemistry; Herrmann, W.A., Ed.; Springer: Berlin/Heidelberg, Germany, 1993; pp. 21-43. [CrossRef]

7. Jiao, L.; Wang, Y.; Jiang, H.L.; Xu, Q. Metal-Organic Frameworks as Platforms for Catalytic Applications. Adv. Mater. 2018, 30, 1703663. [CrossRef] [PubMed]

8. Konnerth, H.; Matsagar, B.M.; Chen, S.S.; Prechtl, M.H.G.; Shieh, F.K.; Wu, K.C.W. Metal-organic framework (MOF)-derived catalysts for fine chemical production. Coord. Chem. Rev. 2020, 416, 213319. [CrossRef]

9. Wang, Q.; Astruc, D. State of the Art and Prospects in Metal-Organic Framework (MOF)-Based and MOF-Derived Nanocatalysis. Chem. Rev. 2020, 120, 1438-1511. [CrossRef]

10. Granadeiro, C.M.; Nogueira, L.S.; Juliao, D.; Mirante, F.; Ananias, D.; Balula, S.S.; Cunha-Silva, L. Influence of a porous MOF support on the catalytic performance of Eu-polyoxometalate based materials: Desulfurization of a model diesel. Catal. Sci. Technol. 2016, 6, 1515-1522. [CrossRef]

11. Granadeiro, C.M.; Ribeiro, S.O.; Karmaoui, M.; Valenca, R.; Ribeiro, J.C.; de Castro, B.; Cunha-Silva, L.; Balula, S.S. Production of ultra-deep sulfur-free diesels using a sustainable catalytic system based on UiO-66(Zr). Chem. Commun. 2015, 51, 13818-13821. [CrossRef]

12. Juliao, D.; Gomes, A.C.; Pillinger, M.; Cunha-Silva, L.; de Castro, B.; Goncalves, I.S.; Balula, S.S. Desulfurization of model diesel by extraction/oxidation using a zinc-substituted polyoxometalate as catalyst under homogeneous and heterogeneous (MIL-101 (Cr) encapsulated) conditions. Fuel Process. Technol. 2015, 131, 78-86. [CrossRef]

13. Juliao, D.; Gomes, A.C.; Pillinger, M.; Valenca, R.; Ribeiro, J.C.; de Castro, B.; Goncalves, I.S.; Cunha Silva, L.; Balula, S.S. Zinc-Substituted Polyoxotungstate@amino-MIL-101(Al)_An Efficient Catalyst for the Sustainable Desulfurization of Model and Real Diesels. Eur. J. Inorg. Chem. 2016, 32, 5114-5122. [CrossRef]

14. Piscopo, C.G.; Granadeiro, C.M.; Balula, S.S.; Boskovi, D. Metal-Organic Framework-Based Catalysts for Oxidative Desulfurization. Chemcatchem 2020, 12, 4721-4731. [CrossRef]

15. Ribeiro, S.; Barbosa, A.D.S.; Gomes, A.C.; Pillinger, M.; Goncalves, I.S.; Cunha-Silva, L.; Balula, S.S. Catalytic oxidative desulfurization systems based on Keggin phosphotungstate and metal-organic framework MIL-101. Fuel Process. Technol. 2013, 116, 350-357. [CrossRef]

16. Viana, A.M.; Ribeiro, S.O.; de Castro, B.; Balula, S.S.; Cunha-Silva, L. Influence of UiO-66(Zr) Preparation Strategies in Its Catalytic Efficiency for Desulfurization Process. Materials 2019, 12, 3009. [CrossRef] [PubMed]

17. Viana, A.M.; Julião, D.; Mirante, F.; Faria, R.G.; de Castro, B.; Balula, S.S.; Cunha-Silva, L. Straightforward activation of metal-organic framework UiO-66 for oxidative desulfurization processes. Catal. Today 2020, in press. [CrossRef] 
18. Cavka, J.H.; Jakobsen, S.; Olsbye, U.; Guillou, N.; Lamberti, C.; Bordiga, S.; Lillerud, K.P. A New Zirconium Inorganic Building Brick Forming Metal Organic Frameworks with Exceptional Stability. J. Am. Chem. Soc. 2008, 130, 13850-13851. [CrossRef]

19. Al-Jadir, T.M.; Siperstein, F.R. The influence of the pore size in Metal-Organic Frameworks in adsorption and separation of hydrogen sulphide: A molecular simulation study. Microporous Mesoporous Mater. 2018, 271, 160-168. [CrossRef]

20. Zheng, J.; Wu, M.; Jiang, F.; Su, W.; Hong, M. Stable porphyrin Zr and Hf metal—Organic frameworks featuring $2.5 \mathrm{~nm}$ cages: High surface areas, SCSC transformations and catalyses. Chem. Sci. 2015, 6, 3466-3470. [CrossRef]

21. Rojas-Buzo, S.; García-García, P.; Corma, A. Catalytic Transfer Hydrogenation of Biomass-Derived Carbonyls over Hafnium-Based Metal-Organic Frameworks. ChemSusChem 2018, 11, 432-438. [CrossRef]

22. Beyzavi, M.H.; Klet, R.C.; Tussupbayev, S.; Borycz, J.; Vermeulen, N.A.; Cramer, C.J.; Stoddart, J.F.; Hupp, J.T.; Farha, O.K. A Hafnium-Based Metal-Organic Framework as an Efficient and Multifunctional Catalyst for Facile $\mathrm{CO}_{2}$ Fixation and Regioselective and Enantioretentive Epoxide Activation. J. Am. Chem. Soc. 2014, 136, 15861-15864. [CrossRef] [PubMed]

23. Cai, X.; Pan, J.; Tu, G.; Fu, Y.; Zhang, F.; Zhu, W. Pd/UiO-66(Hf): A highly efficient heterogeneous catalyst for the hydrogenation of 2,3,5-trimethylbenzoquinone. Catal. Commun. 2018, 113, 23-26. [CrossRef]

24. Zhang, F.; Zheng, S.; Xiao, Q.; Zhong, Y.; Zhu, W.; Lin, A.; El-Shall, M.S. Synergetic catalysis of palladium nanoparticles encaged within amine-functionalized UiO-66 in the hydrodeoxygenation of vanillin in water. Green Chem. 2016, 18, 2900-2908. [CrossRef]

25. Cliffe, M.J.; Wan, W.; Zou, X.; Chater, P.A.; Kleppe, A.K.; Tucker, M.G.; Wilhelm, H.; Funnell, N.P.; Coudert, F.-X.; Goodwin, A.L. Correlated defect nanoregions in a metal-organic framework. Nat. Commun. 2014, 5, 4176. [CrossRef]

26. Hu, Z.; Peng, Y.; Kang, Z.; Qian, Y.; Zhao, D. A Modulated Hydrothermal (MHT) Approach for the Facile Synthesis of UiO-66-Type MOFs. Inorg. Chem. 2015, 54, 4862-4868. [CrossRef]

27. Zhang, X.; Huang, P.; Liu, A.; Zhu, M. A metal—Organic framework for oxidative desulfurization: UIO-66(Zr) as a catalyst. Fuel 2017, 209, 417-423. [CrossRef]

28. Hinde, C.S.; Webb, W.R.; Chew, B.K.J.; Tan, H.R.; Zhang, W.-H.; Hor, T.S.A.; Raja, R. Utilisation of gold nanoparticles on amine-functionalised UiO-66 $\left(\mathrm{NH}_{2}-\mathrm{UiO}-66\right)$ nanocrystals for selective tandem catalytic reactions. Chem. Commun. 2016, 52, 6557-6560. [CrossRef]

29. Sarker, M.; An, H.J.; Jhung, S.H. Adsorptive Removal of Indole and Quinoline from Model Fuel over Various UiO-66s: Quantitative Contributions of H-Bonding and Acid-Base Interactions to Adsorption. J. Phys. Chem. C 2018, 122, 4532-4539. [CrossRef]

30. Valenzano, L.; Civalleri, B.; Chavan, S.; Bordiga, S.; Nilsen, M.H.; Jakobsen, S.; Lillerud, K.P.; Lamberti, C. Disclosing the Complex Structure of UiO-66 Metal Organic Framework: A Synergic Combination of Experiment and Theory. Chem. Mater. 2011, 23, 1700-1718. [CrossRef]

31. Kandiah, M.; Nilsen, M.H.; Usseglio, S.; Jakobsen, S.; Olsbye, U.; Tilset, M.; Larabi, C.; Quadrelli, E.A.; Bonino, F.; Lillerud, K.P. Synthesis and Stability of Tagged UiO-66 Zr-MOFs. Chem. Mater. 2010, 22, 6632-6640. [CrossRef]

32. Ahmadijokani, F.; Ahmadipouya, S.; Molavi, H.; Rezakazemi, M.; Aminabhavi, T.M.; Arjmand, M. Impact of scale, activation solvents, and aged conditions on gas adsorption properties of UiO-66. J. Environ. Manag. 2020, 274, 111155. [CrossRef] [PubMed]

33. Low, J.J.; Benin, A.I.; Jakubczak, P.; Abrahamian, J.F.; Faheem, S.A.; Willis, R.R. Virtual High Throughput Screening Confirmed Experimentally: Porous Coordination Polymer Hydration. J. Am. Chem. Soc. 2009, 131, 15834-15842. [CrossRef] [PubMed]

34. Ahmed, I.; Jhung, S.H. Applications of metal-organic frameworks in adsorption/separation processes via hydrogen bonding interactions. Chem. Eng. J. 2017, 310, 197-215. [CrossRef]

35. García-García, P.; Corma, A. Hf-based Metal-Organic Frameworks in Heterogeneous Catalysis. Israel J. Chem. 2018, 58, 1062-1074. [CrossRef] 